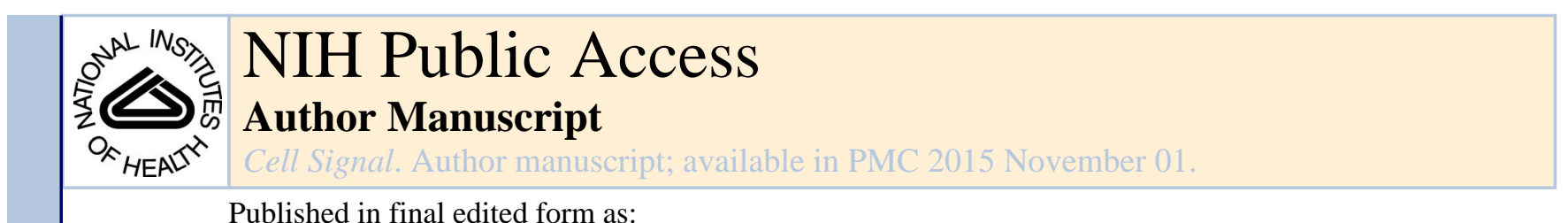

Published in final edited form as:

Cell Signal. 2014 November ; 26(11): 2358-2369. doi:10.1016/j.cellsig.2014.07.018.

\title{
Predicting and validating the pathway of Wnt3a-driven suppression of osteoclastogenesis
}

\author{
Kazunori Hamamura ${ }^{a}{ }^{*}$, Andy Chen ${ }^{b}$, Akinobu Nishimura ${ }^{a, c}$, Nancy Tanjung ${ }^{\mathrm{a}}$, Akihiro \\ Sudo $^{c}$, and Hiroki Yokota ${ }^{a, d}$ \\ aDepartment of Biomedical Engineering, Indiana University Purdue University Indianapolis, \\ Indianapolis, IN 46202, USA \\ bWeldon School of Biomedical Engineering, Purdue University, West Lafayette, IN 47907, USA \\ 'Department of Orthopaedic Surgery, Mie University School of Medicine, Mie 514, Japan \\ dDepartment of Anatomy and Cell Biology, Indiana University School of Medicine, Indianapolis, IN \\ 46202, USA
}

\begin{abstract}
Wnt signaling plays a major role in bone homeostasis and mechanotransduction, but its role and regulatory mechanism in osteoclast development are not fully understood. Through genome-wide in silico analysis, we examined Wnt3a-driven regulation of osteoclast development. Mouse bone marrow-derived cells were incubated with RANKL in the presence and absence of Wnt3a. Using microarray mRNA expression data, we conducted principal component analysis and predicted transcription factor binding sites (TFBSs) that were potentially involved in the responses to RANKL and Wnt3a. The principal component analysis predicted potential Wnt3a responsive regulators that would reverse osteoclast development, and a TFBS prediction algorithm indicated that the AP1 binding site would be linked to Wnt3a-driven suppression. Since c-Fos was upregulated by RANKL and downregulated by Wnt3a in a dose-dependent manner, we examined its role using RNA interference. The partial silencing of c-Fos suppressed RANKL-driven osteoclastogenesis by downregulating NFATc1, a master transcription factor of osteoclast development. Although the involvement of c-Myc was predicted and partially silencing c-Myc slightly reduced the level of TRAP, c-Myc silencing did not alter the expression of NFATc1. Collectively, the presented systems-biology approach demonstrates that Wnt3a attenuates RANKL-driven osteoclastogenesis by blocking c-Fos expression and suggests that mechanotransduction of bone alters the development of not only osteoblasts but also osteoclasts through Wnt signaling.
\end{abstract}

\footnotetext{
(C) 2014 Elsevier Inc. All rights reserved.

"Corresponding author at: Department of Biomedical Engineering, Indiana University Purdue University Indianapolis, SL155, 723 West Michigan Street, Indianapolis, IN 46202 USA. Tel.: +1 317274 1350; fax: +1 317278 2455. hamamurk@iupui.edu (K. Hamamura).

All authors state that they have no conflicts of interest.
} 


\section{Keywords}

Wnt3a; Osteoclasts; RANKL; NFATc1; c-Fos

\section{Introduction}

The WNT gene family includes 19 known secretory signaling molecules which regulate many aspects of embryonic pattern formation as well as migration and development of various cells [1,2]. In the skeletal system, Wnt signaling plays an important role in mechanotransduction, bone homeostasis, and degenerative disorders [2-5]. Among 19 known ligands for members of the frizzled family receptors, Wnt5a activates noncanonical Wnt signaling through a receptor tyrosine kinase-like orphan receptor and stimulates osteoclastogenesis [6]. Wnt10b is required for maintenance of mesenchymal progenitors, and its deficiency leads to loss of bone mass. Wnt14 enhances endochondral ossification and accelerates chondrocyte maturation $[7,8]$.

Wnt3a is a Wnt ligand known to activate canonical Wnt signaling. In canonical Wnt signaling, transcriptional activities mediated by T-cell factor/lymphoid enhancer factor (TCF/LEF) are regulated through the expression of $\beta$-catenin. Although the involvement of Wnt/ $\beta$-catenin signaling in osteoblast development has been characterized $[2,4,9]$, the role of Wnt3a in the regulation of bone-resorbing osteoclasts is not fully understood. While some have reported that Wnt3a attenuates osteoclast development [10,11], others have found that it has little effect on osteoclastogenesis [6]. Using both mouse bone marrow cells and RAW264.7 pre-osteoclast cells, we examined the effects and regulatory mechanism of Wnt3a-driven regulation of osteoclast development.

The question we addressed was: Does Wnt3a inhibit osteoclast development by suppressing expression of NFATc1 (nuclear factor of activated T-cells, cytoplasmic, calcineurindependent 1), a master transcription factor for osteoclastogenesis? If yes, what regulatory molecule mediates Wnt3a-driven downregulation of NFATc1? In order to identify potential signaling molecule(s) that regulate osteoclast development, we conducted genome-wide mRNA expression analysis using a systems-biology approach. Mouse bone marrow cells were incubated with RANKL in the presence and absence of Wnt3a, and the mRNA expression profiles were evaluated in 4 groups of samples (control, RANKL treatment, and RANKL treatment with 2 different doses of Wnt3a). Using principal component analysis [12], we first extracted a set of genes that would attenuate RANKL-driven osteoclast development. Using an ant algorithm [13], we then predicted transcription factor binding sites (TFBS) that are likely to be involved in the responses to RANKL and Wnt3a.

The in silico predictions were evaluated using in vitro experiments with RNA interference. We examined the expression of marker genes for osteoclast development, including tartrateresistant acid phosphatase (TRAP), osteoclast-associated immunoglobulin-like receptor (OSCAR), matrix metalloproteinase 9 (MMP9), cathepsin K, as well as ATPase lysosomal V0 subunit D2 (Atp6v0d2) and dendritic cell-specific transmembrane protein (DcStamp). 


\section{Materials and methods}

\subsection{Cell culture}

Mouse bone marrow cells isolated from long bones (femur and tibia) as well as RAW264.7 mouse pre-osteoclast cells [14] were cultured in aMEM containing $10 \%$ fetal bovine serum and antibiotics (50 units/ml penicillin and $50 \mu \mathrm{g} / \mathrm{ml}$ streptomycin; Life Technologies, Grand Island, NY, USA). Cells were maintained at $37{ }^{\circ} \mathrm{C}$ and $5 \% \mathrm{CO}_{2}$ in a humidified incubator.

\subsection{In vitro osteoclast formation and TRAP (tartrate-resistant acid phosphatase) staining}

Mouse bone marrow cells were plated at $1.2 \times 10^{5}$ and $1.0 \times 10^{6}$ cells into 12-well and 60 $\mathrm{mm}$ dishes, respectively, and cultured with $10 \mathrm{ng} / \mathrm{ml}$ M-CSF (macrophase colonystimulating factor; PeproTech, Rocky Hills, NC, USA) for 3 days. The surface-attached cells were used as osteoclast precursors. These precursors were cultured with $10 \mathrm{ng} / \mathrm{ml}$ M-CSF and $50 \mathrm{ng} / \mathrm{ml}$ RANKL in the presence and absence of Wnt3a. After 2 days of treatment of RANKL, the cells were treated for TRAP staining using an acid phosphatase leukocyte kit (Sigma, St. Louis, MO, USA). The number of TRAP-positive cells containing three or more nuclei was determined. RAW264.7 mouse pre-osteoclast cells were plated at $1.0 \times 10^{5}$ cells into a $60 \mathrm{~mm}$ dish and cultured with $50 \mathrm{ng} / \mathrm{ml}$ RANKL (PeproTech, Rocky Hills, NC, USA) in the presence and absence of Wnt3a (R\&D Systems, Minneapolis, MN, USA).

\subsection{Microarray analysis}

We employed 4 groups of mouse bone marrow cells ( 3 samples per group): control (CN), RANKL (RL), $\mathrm{W}_{100}$ (administration of RANKL and $100 \mathrm{ng} / \mathrm{ml} \mathrm{Wnt} 3 \mathrm{a}$ ), and $\mathrm{W}_{200}$ (administration of RANKL and $200 \mathrm{ng} / \mathrm{ml}$ Wnt3a). The concentration of RANKL was 50 $\mathrm{ng} / \mathrm{ml}$, and all samples were treated with $10 \mathrm{ng} / \mathrm{ml}$ M-CSF. Four hours after incubation with RANKL and Wnt3a, cells were harvested for genome-wide mRNA expression analysis (Affymetrix Mouse Gene 2.0 ST arrays). Expression values were normalized using the Robust Multiarray Average (RMA) algorithm and log2-transformed.

\subsection{Principal component analysis}

For 25,206 genes in the microarray, principal component analysis was conducted using the princomp function in the statistical software tool $\mathrm{R}$ ( $\mathrm{R}$ 3.0.2). Using singular value decomposition, a set of 12 principal component axes (3 samples for each of 4 groups) was determined. In the plane of the first and second principal axes (the two major axes), the four sample groups ( $\mathrm{CN}, \mathrm{RL}, \mathrm{W}_{100}$, and $\mathrm{W}_{200}$ ) were positioned using values in the orthonormal gene vector (right singular vector). We examined whether either or both of the first and second axes could characterize the primary biological response: induction of osteoclastogenesis by RANKL and its suppression by Wnt3a in a dose-dependent manner. Along the major axis that mimics the primary biological response, we derived a list of transcription factors [15] that would be involved in the responses to RANKL and Wnt3a. Furthermore, we used the microarray data to predict potential activators and inhibitors of osteoclastogenesis by determining the significance of the differences in gene expression between groups. Genes whose $p$-values in the three comparisons (RL vs. CN), ( $\mathrm{W}_{200}$ vs. $\mathrm{RL}$ ), and ( $\mathrm{W}_{200}$ vs. $\left.\mathrm{W}_{100}\right)$ were smaller than 0.05 were considered potential regulators. 
Genes that were upregulated by RANKL and downregulated by Wnt3a were called "activators," while genes that were downregulated by RANKL and upregulated by Wnt3a were called "inhibitors."

\subsection{Prediction of transcription factor binding sites (TFBSs)}

Using an ant algorithm-based search method, potential TFBSs were predicted for three sets of comparisons (CN vs. RL, RL vs. $\mathrm{W}_{100}$, and RL vs. $\mathrm{W}_{200}$ ) [13]. In brief, the ant algorithm is a meta-heuristic optimization technique based on the biological behavior of ant colonies. Ants initially wander randomly until they find a food source. When they do, they return to the colony, depositing pheromones along the way. Other ants find and follow these pheromones so that shorter routes to better food sources will be reinforced. In our application, these potential paths consisted of the relative frequency of appearance of TFBSs in the promoter regions (defined as the region 1000-bp upstream of the transcription start site) of a set of relevant genes. In a previous version of this algorithm [13], these TFBSs consisted of all 4-, 5-, or 6-bp combinations of nucleotides. In the current version, TFBSs were obtained using the positional weight matrices of transcription factors from the TRANSFAC 7.0 Public 2005 database [16]. Pheromone levels were determined by calculating the error between the actual gene expression levels and the predicted expression levels from the contributions of the chosen TFBSs.

\subsection{Quantitative real-time PCR}

Total RNA was extracted using an RNeasy Plus mini kit (Qiagen, Germantown, MD, USA). Reverse transcription was conducted with high capacity cDNA reverse transcription kits (Applied Biosystems, Carlsbad, CA, USA), and quantitative real-time PCR was performed using ABI 7500 with Power SYBR green PCR master mix kits (Applied Biosystems). We evaluated mRNA levels of Atp6v0d2 (ATPase, $\mathrm{H}^{+}$transporting lysosomal v0 subunit d2), cathepsin K, c-Fos, DcStamp (dendrocyte expressed seven transmembrane protein), MMP9, NFATc1 (nuclear factor of activated T-cells, cytoplasmic 1), TRAP, and OSCAR (osteoclast-associated receptor) with the PCR primers listed in Table 1. GAPDH was used for internal control. The relative mRNA abundance for the selected genes with respect to the level of GAPDH mRNA was expressed as a ratio of $S_{\text {treated }} / S_{\text {control }}$, where $S_{\text {treated }}=$ mRNA level for the cells treated with RANKL and/or Wnt3a, and $S_{\text {control }}=$ mRNA level for control cells [17].

\subsection{Western blot analysis}

Cells were lysed in a radioimmunoprecipitation assay (RIPA) buffer containing protease inhibitors (Santa Cruz Biotechnology, Santa Cruz, CA, USA) and phosphatase inhibitors (Calbiochem, Billerica, MA, USA). Isolated proteins were fractionated using 10\% SDS gels and electro-transferred to Immobilon-P membranes (Millipore, Billerica, MA, USA). The membrane was incubated for $1 \mathrm{~h}$ with primary antibodies followed by 45 min incubation with goat anti-rabbit, anti-rat, or anti-mouse IgG conjugated with horseradish peroxidase (Cell Signaling, Danvers, MA, USA). We used antibodies against phosphorylated $\beta$-catenin, c-Myc (Cell Signaling), c-Fos (Santa Cruz), NFATc1 (Santa Cruz), cathepsin K (Santa Cruz), OSCAR (R\&D Systems), DcStamp (Millipore), TRAP (Abcam, Cambridge, MA, USA), MMP9 (Abcam), Atp6v0d2 (Aviva Systems Biology, San Diego, CA, USA), and $\beta$ - 
actin (Sigma). Protein levels were assayed using a SuperSignal west femto maximum sensitivity substrate (Thermo Scientific), and signal intensities were quantified with a luminescent image analyzer (LAS-3000, Fuji Film, Tokyo, Japan).

\subsection{Knockdown of c-Myc and c-Fos by siRNA}

RAW264.7 pre-osteoclast cells were treated with siRNA specific to c-Myc (5'-CCA GAU CCC UGA AUU GGA A-3'; Life Technology), or c-Fos (5'-CUA CUU ACA CGU CUU CCU U-3'; Life Technologies). As a nonspecific control, a negative siRNA (UGU ACU GCU UAC GAU UCG G, Life Technologies) was used. Cells were transiently transfected with siRNA for c-Myc, c-Fos or control in Opti-MEM I medium with Lipofectamine RNAiMAX (Life Technologies). Six hours later, the medium was replaced by regular culture medium. The efficiency of silencing was assessed with immunoblotting or quantitative PCR $48 \mathrm{~h}$ after transfection.

\subsection{Statistical analysis}

Three or four independent experiments were conducted, and data were expressed as mean \pm S.D. For comparison among multiple samples, ANOVA followed by post hoc tests was conducted. Statistical significance was evaluated at $p<0.05$. The single and double asterisks and daggers indicate $p<0.05$ and $p<0.01$. To determine intensities in immunoblotting, images were scanned with Adobe Photoshop CS2 (Adobe Systems, San Jose, CA, USA) and quantified using Image $\mathrm{J}$.

\section{Results}

\subsection{Suppression of osteoclast development by Wnt3a}

Administration of RANKL to bone marrow cells significantly increased the number of TRAP-positive multi-nucleated cells (Fig. 1A \& B). In response to 100 or $200 \mathrm{ng} / \mathrm{ml}$ of Wnt3a, the number of TRAP-positive cells was reduced in a dose-dependent manner. The observed suppression of osteoclast development by Wnt3a was associated with a decrease in the phosphorylated form of $\beta$-catenin (p- $\beta$-catenin) as well as NFATc1 (Fig. 1C).

\subsection{Wnt3a-driven reduction in expression of osteoclast specific genes}

Consistent with its reduction of TRAP-positive cells, Wnt3a also decreased the mRNA levels of the selected genes (NFATc1, TRAP, OSCAR, cathepsin K, and MMP9) that were known to be involved in osteoclast development (Fig. 2). The decreases were observed on days 1 and 2 after administration of RANKL in a Wnt3a dose-dependent fashion.

\subsection{Principal component analysis}

In the plane of the first and second principal axes, the four sample groups $\left(\mathrm{CN}, \mathrm{RL}, \mathrm{W}_{100}\right.$, and $\mathrm{W}_{200}$ ) were located (Fig. 3A). The groups were aligned in the order of CN, RL, $W_{100}$, and $\mathrm{W}_{200}$ along the first principal axis (PC1), while the order was $\mathrm{CN}, \mathrm{W}_{200}, \mathrm{~W}_{100}$, and $\mathrm{RL}$ along the second principal axis (PC2). The result indicates that the administration of Wnt3a induced two principal effects: RANKL-like effects along PC1 and anti-RANKL effects along PC2. Since Wnt3a-driven suppression of anti-RANKL effects is consistent with attenuation of osteoclast development, we examined the differentially expressed 
transcription factors that most significantly contribute to PC2 (Fig. 3B \& C). The genes in Fig. 3B were assigned with the largest positive components along PC2, suggesting that they were upregulated by RANKL and downregulated by Wnt3a. The genes in Fig. 3C were identified with the largest negative components along PC2, and they were attenuated by RANKL and stimulated by Wnt3a. The statistical significance of microarray-derived differences in gene expression was also considered in Fig. 3B and C. Transcription factors that are significantly upregulated by RL vs. $\mathrm{CN}$ and downregulated by $\mathrm{W}_{200}$ vs. RL and $\mathrm{W}_{200}$ vs. $\mathrm{W}_{100}$ were listed in Fig. 3B, while transcription factors that are significantly downregulated by RL vs. $\mathrm{CN}$ and upregulated by $\mathrm{W}_{200}$ vs. $\mathrm{RL}$ and $\mathrm{W}_{200}$ vs. $\mathrm{W}_{100}$ are shown in Fig. 3C.

\subsection{Prediction of AP1 as a potential TFBS of Wnt3a-driven regulation}

To predict a transcription factor that may mediate the observed responses to RANKL and Wnt3a, we conducted in silico evaluation of genome-wide mRNA expression profiles using the ant algorithm. From the four groups, we applied the ant algorithm to three comparisons: RANKL vs. control, $\mathrm{W}_{100}$ vs. RANKL, and $\mathrm{W}_{200}$ vs. RANKL. In all three comparisons, the algorithm predicted AP1 and Sox17 as potential TFBSs (Fig. 4). Other TFBS candidates such as AP4, Ets, Rreb1, Stat3, and USF appeared twice in three comparisons.

\subsection{Evaluation of c-Myc}

The involvement of c-Myc in osteoclast development is implied in previous studies, but the reported role is not consistent. Since Myc was predicted as a potential activator (Fig. 3B), we examined its effects on RANKL-induced osteoclastogenesis. In primary bone marrow cells, the mRNA level of c-Myc was elevated by RANKL, and its elevation was partially suppressed by Wnt3a in a dose-dependent manner at $4 \mathrm{~h}$ after RANKL/Wnt3a administration (Fig. 5A). The protein level of c-Myc was also increased by RANKL and reduced by Wnt3a at $200 \mathrm{ng} / \mathrm{ml}$ at 5, 10, and $24 \mathrm{~h}$ after administration of RANKL and Wnt3a (Fig. 5B-E). Compared to non-specific control siRNA (NC), partial silencing of cMyc in RAW264.7 cells slightly reduced the level of TRAP (Fig. 6A, B \& D). However, the mRNA and protein levels of NFATc1 were unchanged by c-Myc siRNA (Fig. 6A-C). Furthermore, treatment with c-Myc siRNA significantly elevated the levels of MMP9 and cathepsin K (Fig. 6B, D \& E).

\subsection{Wnt3a-driven downregulation of c-Fos}

The principal component analysis indicated the potential involvement of c-Fos as an activator of osteoclast development, and the ant algorithm predicted AP1 as a possible cause of differential mRNA expression profiles in the comparisons of RANKL vs. control, $\mathrm{W}_{100}$ vs. RANKL, and $\mathrm{W}_{200}$ vs. RANKL. Using quantitative PCR, we confirmed that the mRNA level of c-Fos was elevated at $4 \mathrm{~h}$, day 1, and day 2, and this elevation was decreased by 200 $\mathrm{ng} / \mathrm{ml}$ of Wnt3a (Fig. 7A). Regarding the protein level of c-Fos, RANKL-driven elevation was reduced by $200 \mathrm{ng} / \mathrm{ml}$ of Wnt3a on day 1 (Fig. 7B \& C). At 2 to 24-h time points, RANKL elevated c-Fos at 10, and $24 \mathrm{~h}$ as well as p- $\beta$-catenin and NFATc1 at $24 \mathrm{~h}$ (Fig. 7D $\&$ E). These elevations were significantly suppressed by $200 \mathrm{ng} / \mathrm{ml}$ of Wnt3a. 


\subsection{Regulation of osteoclast-related genes by c-Fos RNA interference}

In response to RANKL, RAW264.7 cells treated with c-Fos siRNA resulted in a decrease in the protein level of NFATc1 (Fig. 8A). In the presence of RANKL, the c-Fos treated cells showed a statistically significant decrease in the mRNA and protein levels of NFATc1, TRAP, and cathepsin K (Fig. 8B-D). The mRNA and protein levels of OSCAR and MMP9 were also decreased, but the decreases were not statistically significant (Fig. 8B, D, \& E). In RANKL-untreated cells, however, partial silencing of c-Fos had little effect on the mRNA levels of these selected genes.

\subsection{Downregulation of Atp6v0d2 and DcStamp by Wnt3a}

The mRNA levels of the two genes involved in membrane fusion for osteoclast's multinucleation, Atp6v0d2 and DcStamp, were elevated by RANKL, and this elevation was reduced by Wnt3a (Fig. 9A \& B). In response to c-Fos siRNA treatment, RANKL-driven upregulation of the mRNA and protein levels of Atp6v0d2 was significantly decreased, but the level of DcStamp mRNA was unaffected (Fig. 9C \& D).

\section{Discussion}

Wnt3a is known to play a critical role in the skeletal system, including in inflammatory processes, bone formation, and bone resorption [10,11,18,19]. In particular, Wnt3a is an important responder to mechanical stimulation by activating canonical Wnt signaling $[20,21]$. Although the mechanism of activation of bone-forming osteoblasts through interactions with Lrp5/Lrp6 receptor has been investigated [22], the mechanism of inhibition of bone-resorbing osteoclasts has not been well understood. Previous studies presented conflicting results on the role of Wnt3a in osteoclastogenesis $[6,10,11]$. In this study, we employed a systems-biology approach with in silico predictions using genome-wide mRNA expression profiles and in vitro evaluations using RNA interference and investigated the effects of Wnt3a as well as a regulatory mechanism ofWnt3a's action.

The present study shows that RANKL-driven osteoclast development is significantly attenuated by Wnt3a, which acts as a secretory ligand for canonical Wnt signaling. Mouse bone marrow cells elevated the phosphorylation level of $\beta$-catenin in response to RANKL, while the administration of Wnt3a suppressed its elevation. NFATc1 is considered a master transcription factor for osteoclast development [23], and its elevation by RANKL was also reduced by Wnt3a. Similarly, RANKL-inducible osteoclast marker genes such as TRAP, OSCAR, and cathepsin K were all reduced by Wnt3a. In silico data interpretation using principal component analysis and the ant algorithm predicted potential signaling mechanisms for transcriptional regulation. Herein, we specifically evaluated the role of cMyc and c-Fos in the responses to RANKL and Wnt3a using RNA interference. The results support the notion that activation of osteoclast development by RANKL is suppressed by Wnt3a in a c-Fos-mediated pathway.

Using singular value decomposition, we applied principal component analysis for the identification of a set of transcription factors that would potentially be involved in the responses to RANKL and Wnt3a. We first composed an mRNA expression matrix with 12 columns (triplicate samples for each of the four groups). Among 12 eigenvalues, the second 
principal component corresponding to the second largest eigenvalue aligned 4 groups in the order of control, $\mathrm{W}_{200}, \mathrm{~W}_{100}$, and RANKL. This order is consistent with the expected role of Wnt3a as a suppressor of RANKL-driven induction of osteoclastogenesis. Since the first primary axis gave the order of control, RANKL, $\mathrm{W}_{100}$, and $\mathrm{W}_{200}$, the role of Wnt3a is not simply anti-RANKL. The second principal components of the right singular matrix weigh contributions of all transcription factors to the favorable ordering of 4 groups. As a complementary approach to principal component analysis, we employed the ant algorithm and predicted TFBSs for three sets of comparisons (control vs. RANKL, RANKL vs. $\mathrm{W}_{100}$, and RANKL vs. $\left.\mathrm{W}_{200}\right)$. The algorithm is a heuristic search engine using an artificial pheromone as a measure of fitness of TFBSs.

Any result from in silico analysis requires experimental evaluation. In this study, we focused on evaluating potential roles of c-Myc and c-Fos in osteoclast development using RNA interference. The role of c-Myc in osteoclastogenesis is controversial. It is reported that cMyc promotes osteoclast differentiation [24,25], and inhibition of c-Myc using dominant negative c-Myc or a pharmacological inhibitor blocked its differentiation and function. It is also reported, however, that transcription of TRAP is negatively regulated by c-Myc [26]. In the current study, we employed partial silencing of c-Myc and showed that c-Myc siRNA slightly suppressed RANKL-induced TRAP expression but it oppositely upregulated expression of MMP9 and cathepsin K. Collectively, although it is reported that c-Myc can be regulated by the binding of $\beta$-catenin to TCF/LEF [27], c-Myc is not considered as a critical inhibitory factor in response to RANKL andWnt3a, and its role may depend on developmental stages or cellular microenvironment.

Fos proteins belong to the AP1 family, together with Jun and ATF proteins [28]. Like other Fos proteins such as FosB, Fra1, and Fra2, c-Fos plays a major role in osteoclastogenesis [29,30]. However, for the first time, a direct linkage has been established in which c-Fos mediates Wnt3a-driven suppression of osteoclastogenesis in response to RANKL.

Furthermore, the results herein clearly show dose-dependent, target-selective suppressive activities of c-Fos. Although Wnt $3 \mathrm{a}$ at $100 \mathrm{ng} / \mathrm{ml}$ significantly attenuated the number of TRAP-positive multinucleated osteoclasts, it hardly changed the mRNA and protein levels of c-Fos. Treatment with siRNA specific to c-Fos downregulated most of the selected genes involved in osteoclast development, but it did not affect the expression of DcStamp. As shown in the heatmap of transcription factors in Fig. 3, it is likely that other transcription factors are also involved in the responses to Wnt3a.

Besides c-Fos, other transcription factors are likely to be involved in Wnt3a-driven attenuation of osteoclast development. Those factors might be activators for osteoclastogenesis such as c-Fos, as well as inhibitors. In analysis of TFBS with the ant algorithm, Sox 17 is predicted as a potential regulator of the responses to RANKL and Wnt3a. It is reported that Sox 17 modulates Wnt3a/ $\beta$-catenin-mediated transcriptional activities of LEF [31]. In analysis of transcription factors with principal component analysis, potential inhibitors include Foxn3 and Foxa2, which are forkhead box proteins. A variety of forkhead box proteins are involved in stress responses as well as cell metabolism [32], and it is to be examined whether there would be any linkage of $\mathrm{Wnt} 3 \mathrm{a} / \beta$-catenin to stress responses or cell metabolism. Along the first principal axis, transcription factors such as Stat1 and 
Ppary were predicted. Although their involvement in osteoclast development is reported [33,34], they are not likely to be involved in the response to Wnt3a.

In summary, this study demonstrates that Wnt3a suppresses RANKL-driven osteoclastogenesis in a dose-dependent manner, and its action is in part mediated by c-Fos. This action corresponded with the second primary axis in principal component analysis. We think that the systems-biology approach taken in this study can facilitate the interpretation of genome-wide expression profiles and identification of key regulatory players in complex biological processes such as osteoclast development.

\section{Acknowledgments}

The authors appreciate M. Hamamura and J.W. Shim for their technical assistance and Y. Liu for the curated list of transcription factor positional weight matrices. Research reported in this publication was supported by NIH R01AR052144 and CTSA UL1-TR000157. The content is solely the responsibility of the authors and does not necessarily represent the official views of the National Institutes of Health.

\section{References}

1. Willert K, Nusse R. Cold Spring Harb Perspect Biol. 2012; 4:a007864. [PubMed: 22952392]

2. Monroe DG, McGee-Lawrence ME, Oursler MJ, Westendorf JJ. Gene. 2012; 492:1-18. [PubMed: 22079544]

3. Robling AG, Turner CH. Cirt Rev Eukaryot Gene Expr. 2009; 19:319-338.

4. Baron R, Kneissel M. Nat Med. 2013; 19:179-192. [PubMed: 23389618]

5. Miao C, Yang Y, He X, Li X, Huang C, Huang Y, Zhang L, Lv X, Jin Y, Li J. Cell Signal. 2013; 25:2069-2078. [PubMed: 23602936]

6. Maeda K, Kobayashi Y, Udagawa N, Uehara S, Ishihara A, Mizoguchi T, Kikuchi Y, Takada I, Kato S, Kani S, Nishita M, Marumoto K, Martin TJ, Minami Y, Takahashi N. Nat Med. 2012; 18:405-412. [PubMed: 22344299]

7. Stevens JR, Miranda-Carboni GA, Singer MA, Brugger SM, Lyons KM, Lane TF. J Bone Miner Res. 2010; 25:2138-2147. [PubMed: 20499361]

8. Day TF, Guo X, Garrett-Beal L, Yang Y. Dev Cell. 2005; 8:739-750. [PubMed: 15866164]

9. Tamura M, Uyama M, Sugiyama Y, Sato M. Mol Med Rep. 2013; 8:1807-1811. [PubMed: 24100761]

10. Qiang Y-W, Shaughnessy JD Jr, Yaccoby S. Blood. 2008; 112:374-382. [PubMed: 18344425]

11. Albers J, Keller J, Baranowsky A, Beil FT, Catala-Lehnen P, Schulze J, Amling M, Schinke T. J Cell Biol. 2013; 200:537-549. [PubMed: 23401003]

12. Raychaudhuri S, Stuart JM, Altman RB. Pac Symp Biocomput. 2000:455-466. [PubMed: 10902193]

13. Chen A, Hamamura K, Wang G, Xing W, Mohan S, Yokota H, Liu Y. Genom Proteomics Bioinforma. 2007; 5:158-165.

14. Hsu H, Lacey DL, Dunstan CR, Solovyev I, Colombero A, Timms E, Tan HL, Elliott G, Kelley MJ, Sarosi I, Wang L, Xia XZ, Elliott R, Chiu L, Black T, Scully S, Capparelli C, Morony S, Shimamoto G, Bass MB, Boyle WJ. Proc Natl Acad Sci U S A. 1999; 96:3540-3545. [PubMed: 10097072]

15. Kanamori M, Konno H, Osato N, Kawai J, Hayashizaki Y, Suzuki H. Biochem Biophys Res Commun. 2004; 322:787-793. [PubMed: 15336533]

16. Matys V, Fricke E, Geffers R, Gössling E, Haubrock M, Hehl R, Hornischer K, Karas D, Kel AE, Kel-Margoulis OV, Kloos DU, Land S, Lewicki-Potapov B, Michael H, Münch R, Reuter I, Rotert S, Saxel H, Scheer M, Thiele S, Wingender E. Nucleic Acids Res. 2003; 31:374-378. [PubMed: 12520026]

17. Hamamura K, Zhang P, Yokota H. Cell Biol Int. 2008; 32:1238-1246. [PubMed: 18675921] 
18. Nakashima A, Katagiri T, Tamura M. J Biol Chem. 2005; 280:37660-37668. [PubMed: 16150699]

19. Winkler DG, Sutherland MSK, Ojala E, Turcott E, Geoghegan JC, Shpektor D, Skonier JE, Yu C, Latham JA. J Biol Chem. 2005; 280:2498-2502. [PubMed: 15545262]

20. Robinson JA, Chatterjee-Kishore M, Yaworsky PJ, Cullen DM, Zhao W, Li C, Kharode Y, Sauter L, Babij P, Brown EL, Hill AA, Akhter MP, Johnson ML, Recker RR, Komm BS, Bex FJ. J Biol Chem. 2006; 281:31720-31728. [PubMed: 16908522]

21. Santos A, Bakker AD, Zandieh-Doulabi B, Semeins CM, Klein-Nulend J. J Orthop Res. 2009; 27:1280-1287. [PubMed: 19353691]

22. Kato M, Patel MS, Levasseur R, Lobov I, Chang BHJ, Glass DA II, Hartmann C, Li L, Hwang T, Brayton CF, Lang RA, Karsenty G, Chan L. J Cell Biol. 2002; 157:303-314. [PubMed: 11956231]

23. Takayanagi H, Kim S, Koga T, Nishina H, Isshiki M, Yoshida H, Saiura A, Isobe M, Yokochi T, Inoue J, Wagner EF, Mak TW, Kodama T, Taniguchi T. 2002; 3:889-901.

24. Battaglino R, Kim D, Fu J, Vaage B, Fu X-Y, Stashenko P. J Bone Miner Res. 2002; 17:763-773. [PubMed: 12009006]

25. Indo Y, Takeshita S, Ishii K, Hoshii T, Aburatani H, Hirao A, Ikeda K. J Bone Miner Res. 2013; 28:2392-2399. [PubMed: 23661628]

26. Daumer KM, Taparowsky EJ, Hall DJ, Steinbeck MJ. J Bone Miner Res. 2002; 17:1701-1709. [PubMed: 12211441]

27. Morin PJ. BioEssays. 1999; 21:1021-1030. [PubMed: 10580987]

28. Wagner EF. Ann Rheum Dis. 2002; 61:ii40-ii42. [PubMed: 12379619]

29. Grigoriadis AE, Wang ZQ, Cecchini MG, Hofstetter W, Felix R, Fleisch HA, Wagner EF. Science. 1994; 266:443-448. [PubMed: 7939685]

30. Wagner EF, Matsuo K. Ann Rheum Dis. 2003; 62:ii83-ii85. [PubMed: 14532157]

31. Liu X, Luo M, Xie W, Wells JM, Goodheart MJ, Ehgelhardt JF. Am J Physiol Lung Cell Mol Physiol. 2010; 299:L694-L710. [PubMed: 20802155]

32. Lam EW, Bronsens JJ, Gomes AR, Koo CY. Nat Rev Cancer. 2013; 13:482-495. [PubMed: 23792361]

33. Takayanagi H, Kim S, Koga T, Taniguchi T. J Cell Biochem. 2005; 94:232-240. [PubMed: 15546140]

34. Wan Y. Trends Endocrinol Metab. 2010; 21:722-728. [PubMed: 20863714] 

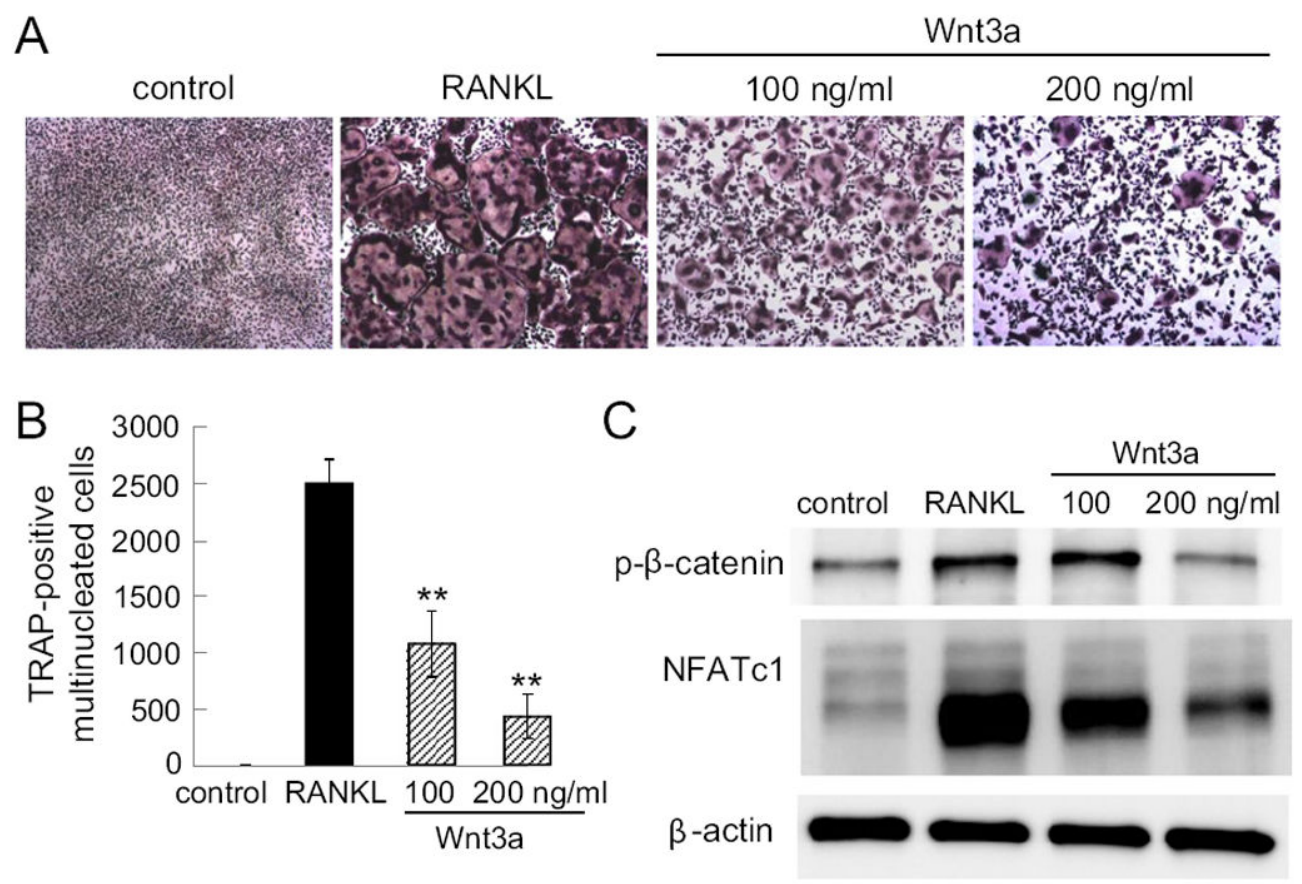

Fig. 1.

Inhibitory effects of Wnt3a on the development of osteoclasts in bone marrow cells. (A) Dose-dependent suppression of TRAP-positive multinucleated osteoclasts by Wnt3a. (B) Number of TRAP-positive multinucleated cells. Note that the double asterisk indicates $p<$ 0.01. (C) Wnt3a-driven inhibition of phosphorylated $\beta$-catenin ( $\mathrm{p}-\beta$-catenin) and NFATc1on day 1 . 

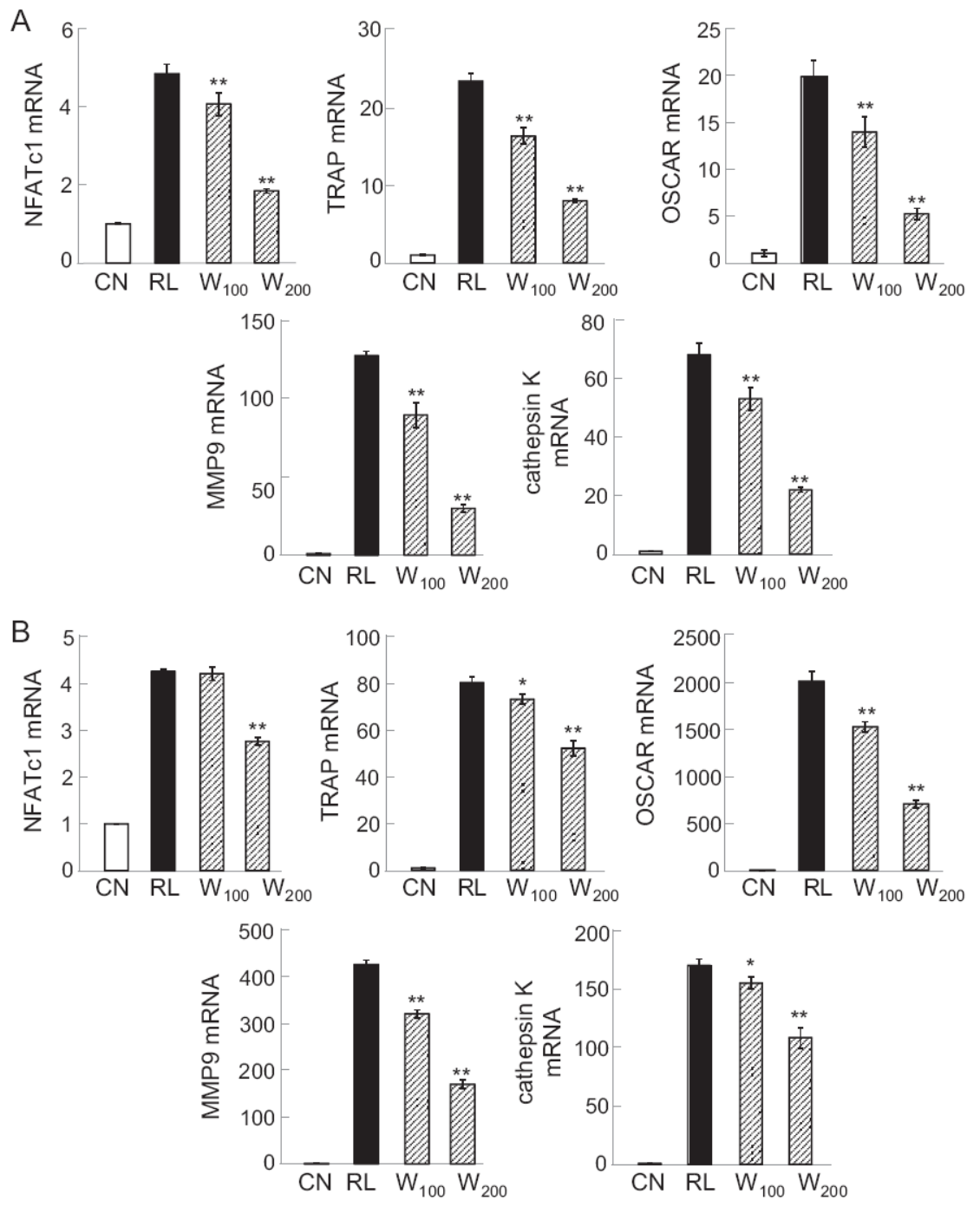

Fig. 2.

Wnt3a-induced reduction of the relative mRNA expression levels of the genes (NFATc1, TRAP, OSCAR, MMP9, and cathepsin K) linked to osteoclastogenesis on days 1 and 2 in bone marrow cells. Note that $\mathrm{CN}=$ control, $\mathrm{RL}=\mathrm{RANKL}, \mathrm{W}_{100}=\mathrm{Wnt} 3 \mathrm{a}$ at $100 \mathrm{ng} / \mathrm{ml}$, and $\mathrm{W}_{200}=\mathrm{Wnt} 3 \mathrm{a}$ at $200 \mathrm{ng} / \mathrm{ml}$. (A) Expression levels on day 1. (B) Expression levels on day 2. 


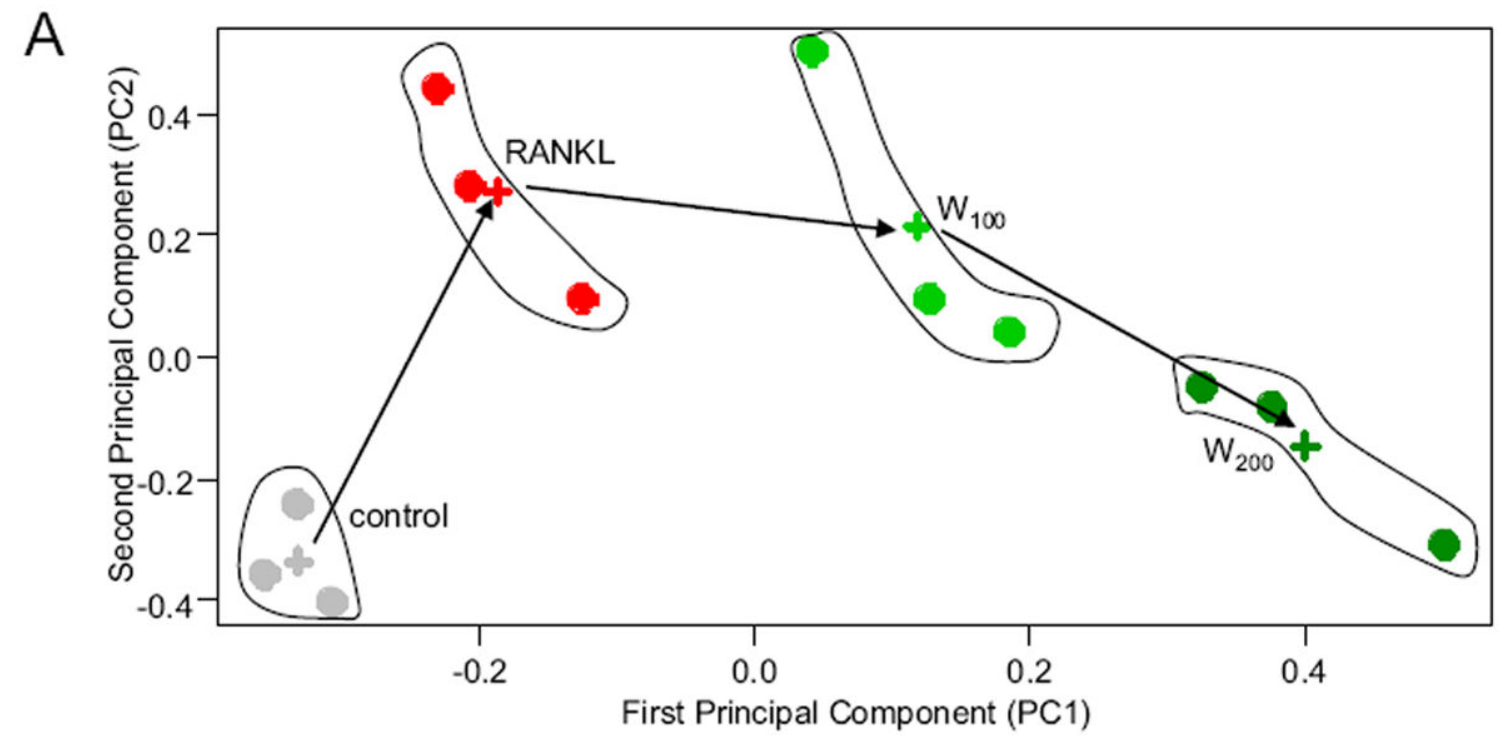

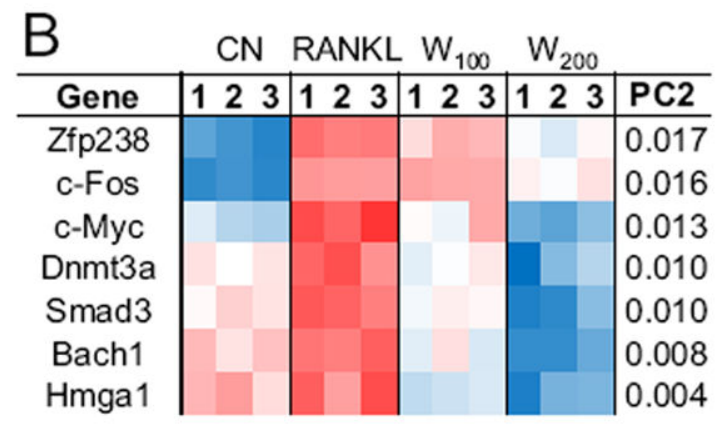

1

\section{Fig. 3.}

Principal component analysis and heatmap of transcription factors potentially involved in osteoclast development. Note that $\mathrm{W}_{100}=\mathrm{Wnt} 3 \mathrm{a}$ at $100 \mathrm{ng} / \mathrm{ml}$, and $\mathrm{W}_{200}=\mathrm{Wnt} 3 \mathrm{a}$ at 200 ng/ml. (A) Two-dimensional clustering map of 4 sample groups (control, RANKL, $W_{100}$, and $\mathrm{W}_{200}$ ) on the plane of the first and second principal axes. The colored cross indicates the center of gravity for the corresponding sample group. (B \& C) Heatmap of potential activating and inhibiting transcription factors, respectively, selected from the second principal axis. 
RANKL/Control

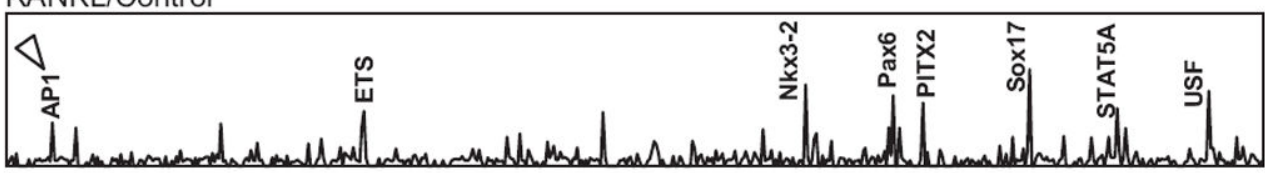

$\mathrm{W}_{100} / \mathrm{RANKL}$

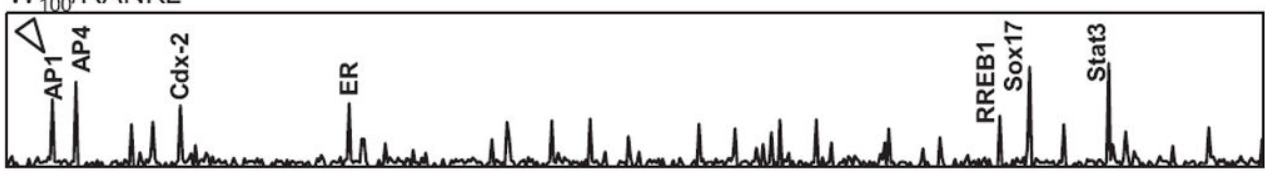

$\mathrm{W}_{200} / \mathrm{RANKL}$

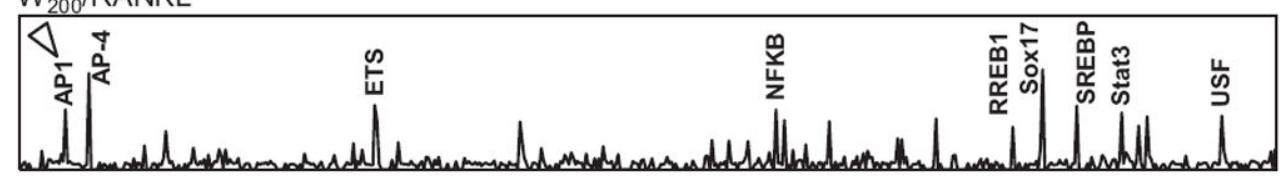

Pheromone levels for potential transcription factors $(A-Z)$

Fig. 4.

Genome-wide prediction of potential transcription factors in response to RANKL and Wnt3a. The pheromone levels in the ant algorithm are plotted for the three comparisons, including RANKL vs, control, $\mathrm{W}_{100}$ vs. RANKL, and $\mathrm{W}_{200}$ vs. RANKL. TFBS with elevated pheromone levels are labeled. Note that $\mathrm{W}_{100}=\mathrm{Wnt} 3 \mathrm{a}$ at $100 \mathrm{ng} / \mathrm{ml}$, and $\mathrm{W}_{200}=$ $\mathrm{Wnt} 3 \mathrm{a}$ at $200 \mathrm{ng} / \mathrm{ml}$. 


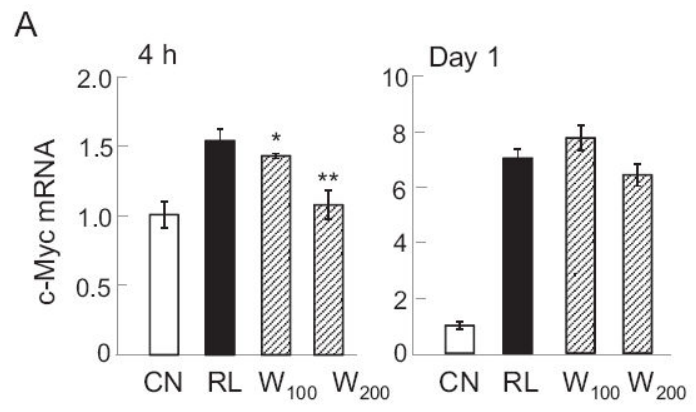

B
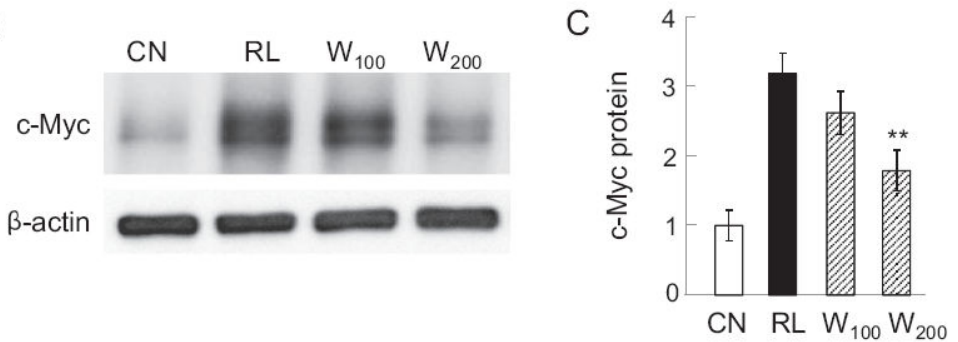

D
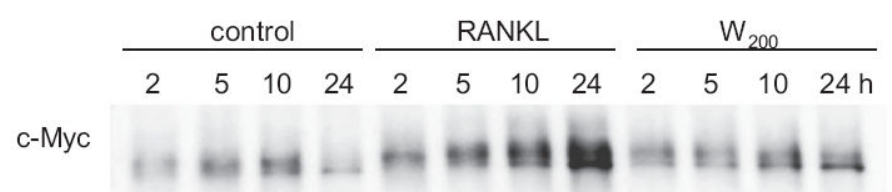

$\beta$-actin

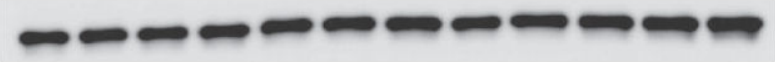

E

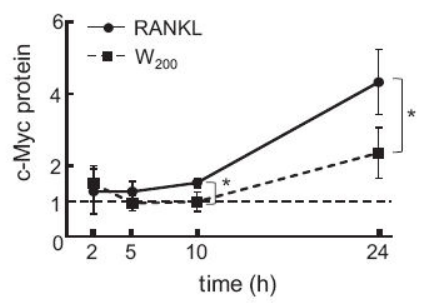

Fig. 5.

Evaluation of c-Myc expression in bone marrow cells. Note that $\mathrm{CN}=$ control, $\mathrm{RL}=$ RANKL, $\mathrm{W}_{100}=\mathrm{Wnt} 3 \mathrm{a}$ at $100 \mathrm{ng} / \mathrm{ml}$, and $\mathrm{W}_{200}=\mathrm{Wnt} 3 \mathrm{a}$ at $200 \mathrm{ng} / \mathrm{ml}$. (A) mRNA level of c-Myc in response to RANKL and Wnt3a at $4 \mathrm{~h}$ and day 1. (B \& C) Protein level of c-Myc in response to RANKL and Wnt3a on day 1. (D) Protein level of c-Myc at 2, 5, 10, and $24 \mathrm{~h}$ after administration of RANKL/Wnt3a. (E) Protein level of c-Myc at 2, 5, 10, and $24 \mathrm{~h}$. The normalized level of " 1 " was defined as the level for the cells without RANKL or Wnt3a. 
A

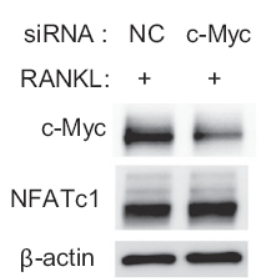

B

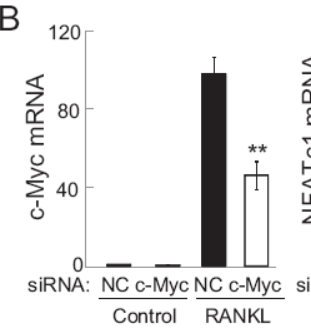

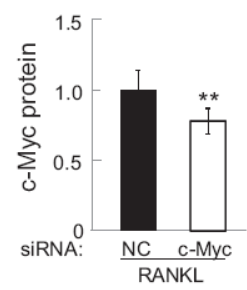

15

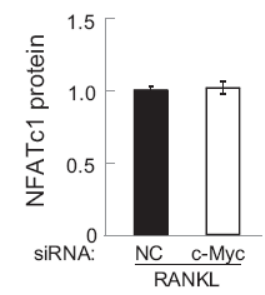

C
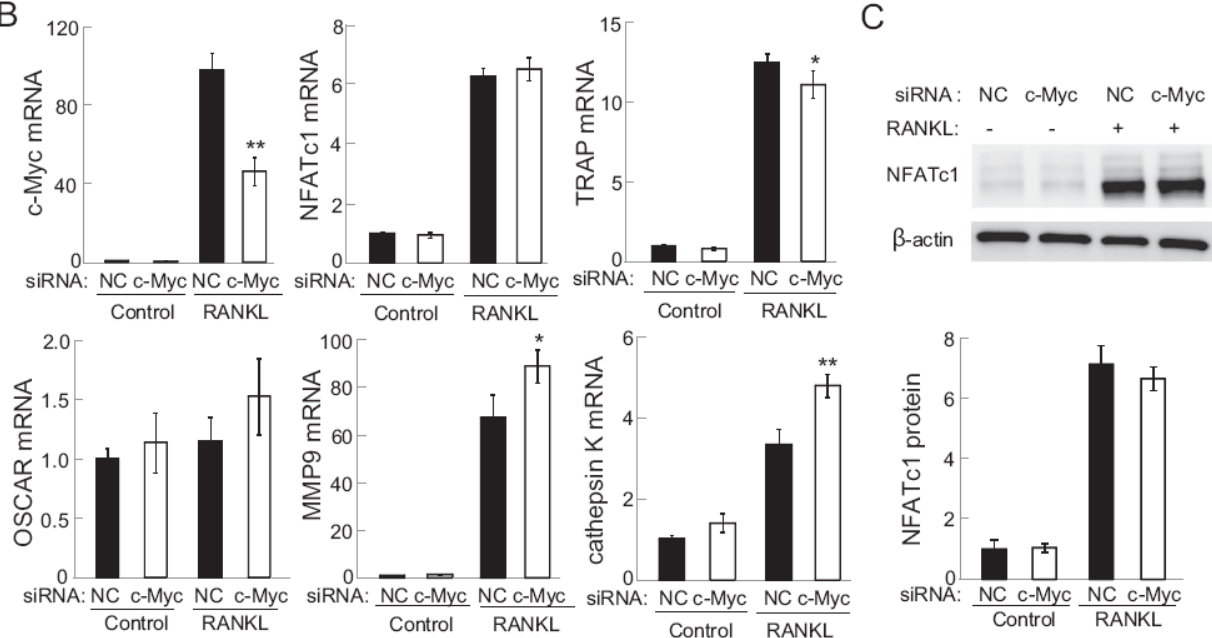

D
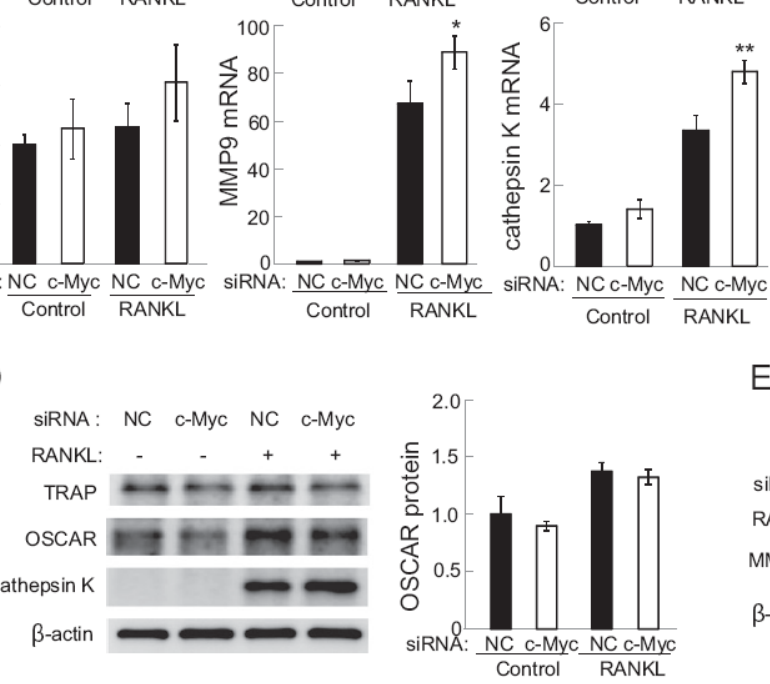

E
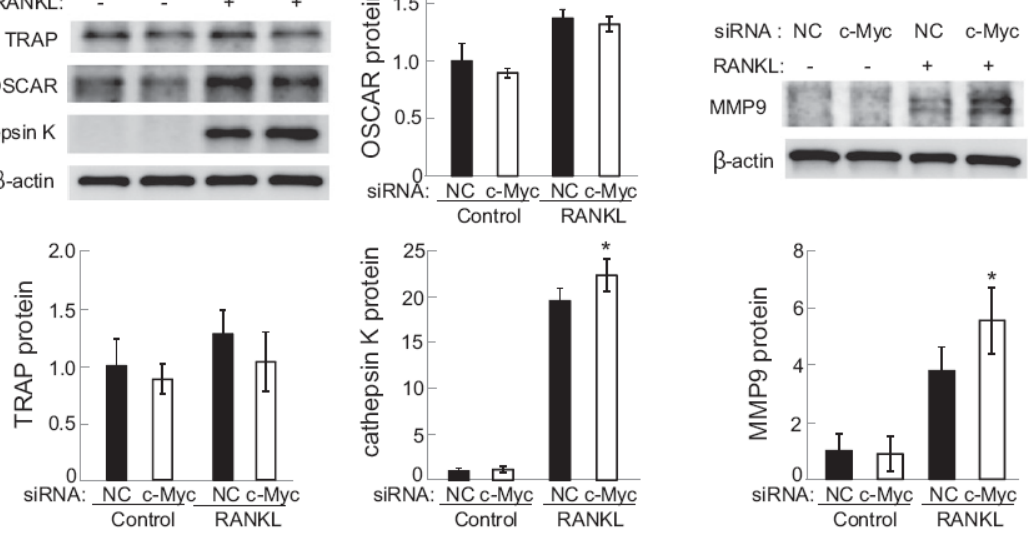

Fig. 6.

Effects of c-Myc siRNA on the selected genes involved in osteoclast development (NFATc1, TRAP, OSCAR, MMP9, and cathepsin K) in RAW264.7 cells. (A) Protein levels of c-Myc and NFATc1 in response to c-Myc siRNA in the presence of RANKL. (B) mRNA levels of c-Myc, NFATc1, TRAP, OSCAR, MMP9, and cathepsin K in response to nonspecific control siRNA (NC) and c-Myc siRNA. (C) NFATc1 protein level after c-Myc siRNA treatment in the presence and absence of RANKL for 1 day. (D) Protein levels of TRAP, OSCAR, and cathepsin K after c-Myc siRNA treatment in the presence and absence of RANKL for 2 days. (E) Protein levels of MMP9 after c-Myc siRNA treatment in the presence and absence of RANKL for 3 days. 

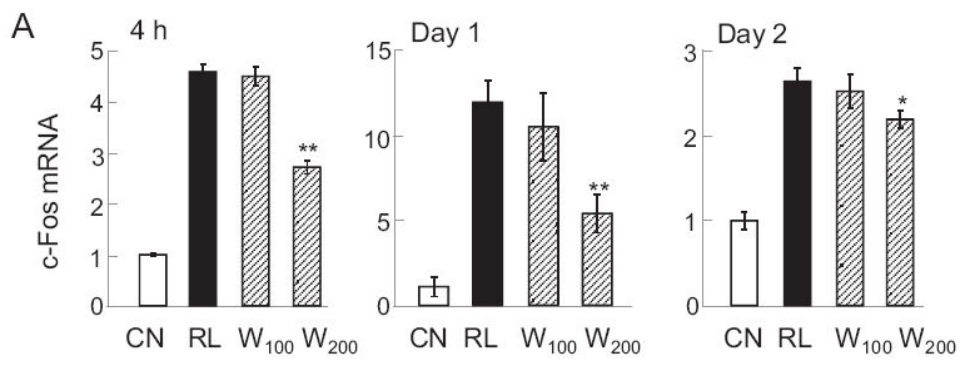

B
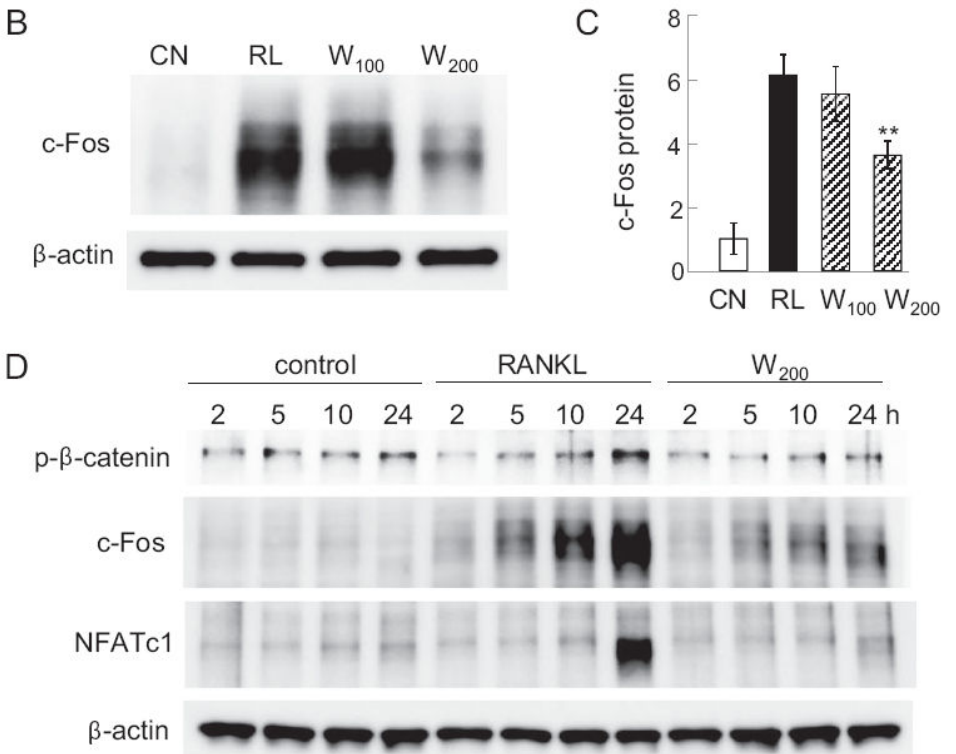

E
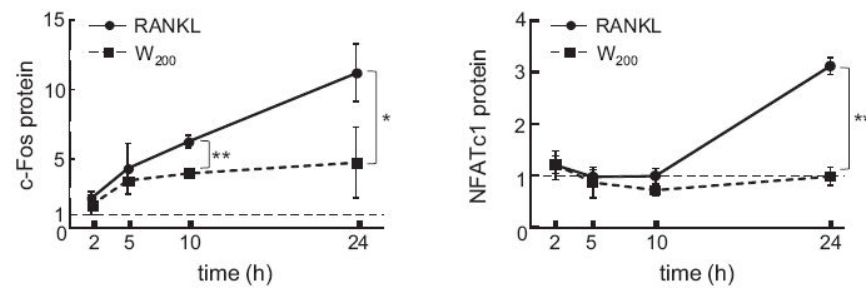

Fig. 7.

Wnt3a-driven reduction in c-Fos in bone marrow cells. Note that $\mathrm{CN}=$ control, $\mathrm{RL}=$ RANKL, $\mathrm{W}_{100}=\mathrm{Wnt} 3 \mathrm{a}$ at $100 \mathrm{ng} / \mathrm{ml}$, and $\mathrm{W}_{200}=\mathrm{Wnt} 3 \mathrm{a}$ at $200 \mathrm{ng} / \mathrm{ml}$. The single and double asterisks indicate $p<0.05$ and $p<0.01$, respectively. (A) c-Fos mRNA levels (4 h, day 1, and day 2). (B) c-Fos protein level on day 1. (C) Comparison of protein levels of cFos. The normalized level of " 1 " was defined as the level for the cells that were not treated with RANKL without administration of Wnt3a. (D) Protein levels of p- $\beta$-catenin, c-Fos, and NFATc1 at 2, 5, 10, and $24 \mathrm{~h}$. (E) Protein levels of c-Fos and NFATc1 at 2, 5, 10, and $24 \mathrm{~h}$. The normalized level of " 1 " was defined as the level for the cells without RANKL or Wnt3a. 


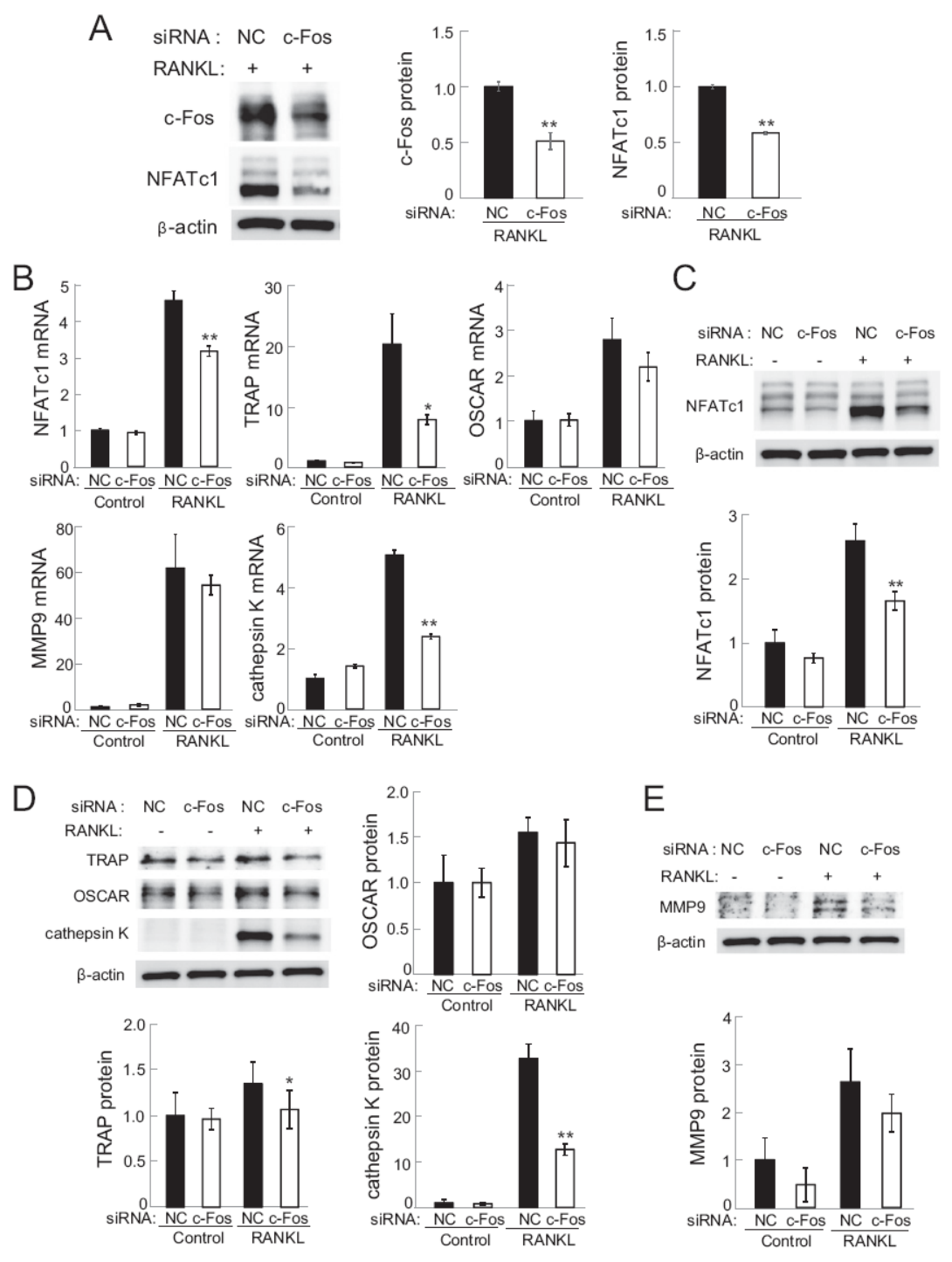

Fig. 8.

Suppression of RANKL-driven osteoclast development by c-Fos siRNA in RAW264.7 cells. (A) Protein levels of c-Fos and NFATc1 with c-Fos siRNA in the presence of RANKL. (B) mRNA levels of NFATc1, TRAP, OSCAR, MMP9, and cathepsin $\mathrm{K}$ in response to nonspecific control siRNA (NC) and c-Fos siRNA. (C) NFATc1 protein level after c-Fos siRNA treatment in the presence and absence of RANKL for 1 day. (D) Protein levels of TRAP, OSCAR, and cathepsin $\mathrm{K}$ after c-Fos siRNA treatment in the presence and absence of RANKL for 2 days. (E) Protein levels of MMP9 after c-Fos siRNA treatment in the presence and absence of RANKL for 3 days. The single and double asterisks indicate $p<$ 0.05 and $p<0.01$, respectively. 


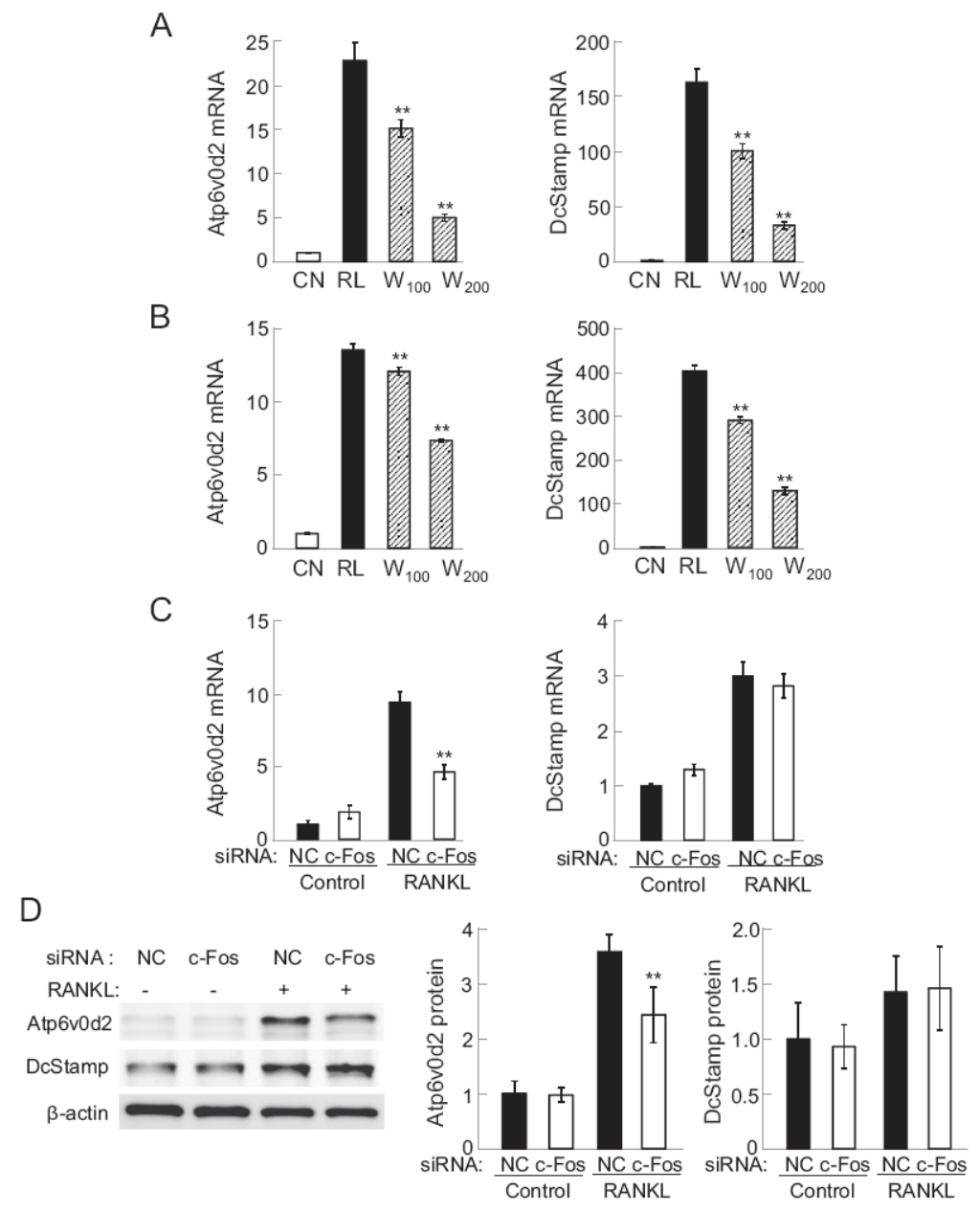

Fig. 9.

Expression of Atp6v0d2 and DcStamp. Note that CN $=$ control, RL $=$ RANKL, $\mathrm{W}_{100}=$ $\mathrm{Wnt} 3 \mathrm{a}$ at $100 \mathrm{ng} / \mathrm{ml}$, and $\mathrm{W}_{200}=\mathrm{Wnt} 3 \mathrm{a}$ at $200 \mathrm{ng} / \mathrm{ml}$. The double asterisk indicates $p<$ 0.01. (A \& B) Wnt3a-driven reduction of Atp6v0d2 mRNA and DcStamp mRNA in bone marrow cells on day 1 and day 2, respectively. (C) mRNA levels of Atp6v0d2 and DcStamp after c-Fos siRNA treatment in the presence and absence of RANKL. "NC" denotes nonspecific control siRNA treatment. (D) Protein levels of Atp6v0d2 and DcStamp after c-Fos siRNA treatment in the presence and absence of RANKL for 2 days. 


\section{Table 1}

Real-time PCR primers used in this study.

\begin{tabular}{|c|c|c|}
\hline Target & Forward primer & Backward primer \\
\hline Atp6vod2 & 5'-AAGCCTTTGTTTGACGCTGT-3' & 5'-TTCGATGCCTCTGTGAGATG-3' \\
\hline cath $\mathrm{K}$ & 5'-CAGCTTCCCCAAGATGTGAT-3' & 5'-AGCACCAACGAGAGGAGAAA-3' \\
\hline c-Fos & 5'-AGGCCCAGTGGCTCAGAGA-3' & 5'-CCAGTCTGCTGCATAGAAGGAA-3' \\
\hline c-Myc & 5'-CAACGTCTTGGAACGTCAGA-3' & 5'-TCGTCTGCTTGAATGGACAG-3' \\
\hline DeStamp & 5'-AAAACCCTTGGGCTGTTCTT-3' & 5'-AATCATGGACGACTCCTTGG-3' \\
\hline MMP9 & 5'-GAAGGCAAACCCTGTGTGTT-3' & 5'-AGAGTACTGCTTGCCCAGGA-3' \\
\hline NFATc1 & 5'-GGTGCTGTCTGGCCATAACT-3' & 5'-GCGGAAAGGTGGTATCTCAA-3' \\
\hline OSCAR & 5'-ACACACACACCTGGCACCTA-3' & 5'-GAGACCATCAAAGGCAGAGC-3' \\
\hline TRAP & 5'-TCCTGGCTCAAAAAGCAGTT-3' & 5'-ACATAGCCCACACCGTTCTC-3' \\
\hline GAPDH & 5'-TGCACCACCAACTGCTTAG-3' & 5'-GGATGCAGGGATGATGTTC-3' \\
\hline
\end{tabular}

